\title{
Focal therapy for localized prostate cancer - choosing the middle ground
}

\author{
Uri Lindner, MD; John Trachtenberg, MD
}

$\mathrm{P}$ rostate cancer ( $\mathrm{PCa}$ ) is the most common noncutaneous human malignancy, with an estimated 24700 cases diagnosed in 2008 in Canada. ${ }^{1}$ Autopsy studies have demonstrated $\mathrm{PCa}$ in $40 \%$ of men aged 60 years, increasing up to $70 \%$ in men aged 80 years. However, the lifetime risk of clinically significant and fatal prostate cancer of a 50-yearold man is estimated to be only $9.5 \%$ and $2.9 \%$, respectively. ${ }^{2}$ Some patients with high-grade and high-volume disease will require treatment, but we are uncertain of the treatment requirements in most without such features. Hence a dilemma is raised: Should we overtreat many patients with wholegland radical treatments who ultimately have insignificant disease, or should we select active surveillance (AS) and potentially miss a window of opportunity for cure for those who ultimately require treatment? The aim of this article is to highlight some of the shortcomings of both of these options in a carefully selected population with PCa and to offer a new treatment option, focal therapy, that would offer better risk-benefit balance and thus serve as a superior middle ground in the management of patients with PCa.

With current trends of prostate-specific antigen (PSA) screening and the lowered PSA threshold for biopsy, 45\% to $85 \%$ of patients fall in the category of low-risk PCa (PSA $<10 \mu \mathrm{g} / \mathrm{L}$, Gleason grade $3+3$, cT1 $\mathrm{c}-\mathrm{cT} 2 \mathrm{a})$. $^{3-5}$ It is estimated that between $25 \%$ and $84 \%$ of PCa patients currently being treated would not succumb to their disease should their PCa be left untreated (insignificant disease). ${ }^{6-11}$ This overtreatment brings back the question Whitmore so eloquently phrased: "Is cure necessary in those in whom it may be possible? Is cure possible in those in whom it may be necessary?"12

Although we risk overtreating a large subset of patients, proponents for active treatment quote the Scandinavian trial which demonstrated a decrease in cancer-specific mortality for patients who underwent radical prostatectomy (RP) rather than watchful waiting (12.5\% v. $17.9 \%)$ and an increase in survival without metastasis $(76.9 \%$ v. $54.4 \%) .713$

However, all available whole-gland treatments exert a significant negative impact on patients' health-related quality of life..$^{14,15}$

To combat potential overtreatment of clinically insignificant cancer, AS has emerged as an alternative management strategy. ${ }^{16}$ Patients who are suspected of having insignificant
PCa based on physical examination, PSA levels and transrectal ultrasound biopsy (TRUS-Bx) results (Gleason grade, no. of positive cores, percentage of core infiltrated by tumour) are actively monitored, and, should the suspicion arise that the disease is progressing or "active" (as opposed to insignificant disease) based on PSA levels (rise or kinetics) and repeat biopsies, the patient would undergo curative whole-gland treatment. This scheme offers curative treatment to patients we believe warrant it, and avoids inflicting unwarranted side effects in patients who have insignificant disease and don't need treatment. ${ }^{16}$

Although AS is theoretically appealing, data are emerging suggesting a significant proportion of patients thought to be curable on AS with selective delayed therapy, who then underwent RP and were found to be incurable (58\% had extraprostatic extension and $8 \%$ had nodal disease). ${ }^{17}$ Because of the inability to reliably assign individual risk of disease progression, the overriding danger is a small but real possibility of progression to death because of the loss of the opportunity for cure during the surveillance period. Further, although AS may appear to have no morbidity, several studies have shown deterioration of quality of life ${ }^{18-20}$ and even deterioration in sexual function..$^{21,22}$ Finally, although AS has gained some popularity, it is still infrequently used. In the United States about $10 \%$ of eligible men are put on AS protocols, ${ }^{23}$ and even in countries in which AS is largely accepted, only $30 \%$ of eligible men are on AS. ${ }^{24}$

Currently the accepted options for treating low-risk PCa patients lie between radical whole-gland treatment and AS. Each has merits and disadvantages (Table 1).

Focal therapy may be likened to a lumpectomy in breast cancer in which only the diseased part of the organ is targeted with minimal impact on the surrounding normal organ. Onik and colleagues $^{25}$ first coined the term "male lumpectomy" for focal ablation of PCa. As such, it appears that focal therapy is a logical extension of the AS concept because it aims to minimize the risk associated with expectant management in that the clinically threatening index $\operatorname{cancer}^{26}$ (Fig. 1 ) is treated while reducing the risk for lifestyle-altering complications associated with whole-gland treatment.

Using cryosurgery to destroy the area of the prostate containing cancer, only $8 \%$ of patients were found to have 
tumours in the contralateral side of the cryoablated region and $90 \%$ of patients maintained potency. ${ }^{25,27}$ Ellis and coauthors ${ }^{28}$ showed in their series of 60 patients undergoing focal cryoablation a remarkable $80.4 \%$ biochemically disease-free. Ninety-two percent of positive biopsies were from the contralateral side and were safely retreated with cryotherapy. Seventy-two percent of patients maintained potency and the overall complication rates were lower than whole-gland cryotherapy with no rectal fistulas, and only $3.6 \%$ mild incontinence that did not require the use of pads.

These trials, although novel and innovative, base the ablative planning on TRUS-Bx alone. They ablate the whole prostate lobe or even perform subtotal ablation of the prostate. However newer techniques have evolved that base their ablation location on imaging the exact location of the index tumour on magnetic resonance imaging (MRI) and base the ablation size on tumour volume contouring derived from the imaging. It stands to reason that the less healthy prostate tissue that is ablated, the less complications will occur. In a recent phase-I clinical trial of image-guided focal photothermal ablation of low-risk PCa in 12 patients, Lindner and colleagues ${ }^{29}$ showed no significant urinary or erectile morbidity coupled with a $67 \%$ biopsy-proven targeted lesion destruction. To truly perform focal therapy it is essential not only to visualize the tumour on imaging beforehand, but also to monitor the ablation in real time. A variety of trial groups are experimenting with differing imaging modalities to achieve these goals for focal therapy including contrast enhanced ultrasonography for photothermal (laser) therapy ${ }^{29}$ and MRI-guided high intensity focused ultrasound therapy $^{30-32}$ and laser ablation. ${ }^{33}$

Some authors have stated that focal therapy is inappropriate because of the multifocality of PCa. Although this may be true in general, up to one-third of patients have been found to have unifocal disease on examination of RP specimens from patients with stage T1c disease. ${ }^{34,35}$ Furthermore, a unifocal unilateral cancer on TRUS-Bx highly correlates with unifocal disease in the RP specimen. ${ }^{34}$ The index lesion was found to account for $80 \%$ of tumour volume and $92 \%$ of extracapsular invasions arose from the index lesion. ${ }^{66,35}$ In addition, multifocal cancers did not lead to poorer outcomes. If one looks closely at the Scandinavian prostate cancer trial data, patients with extracapsular tumour growth had 14 times the risk of death from PCa as those without it. ${ }^{13}$ If one combines all the above data it would suggest that by applying focal ablation to low-risk patients, one might speculate that up to one-third of patients might be cured. In patients with multifocal disease, treatment of the index lesion alone might prevent extracapsular extension, disease progression and PCa-related mortality.

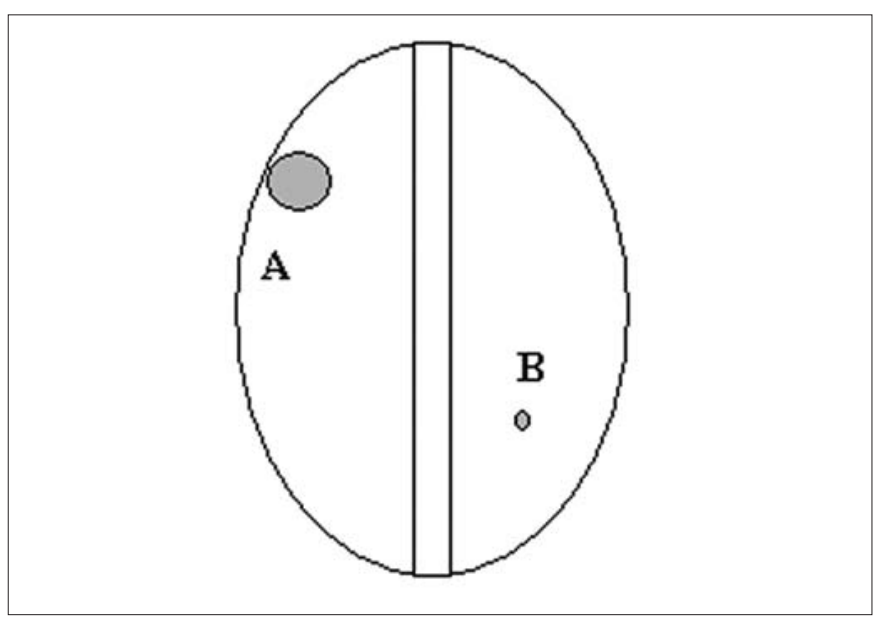

Fig. 1. The index tumour, the biggest tumour, has propensity for extracapsular extension and metastasis (A). The insignificant tumour, smaller than $0.5 \mathrm{~mL}$, has very low propensity for extracapsular extension and metastasis (B).

\section{Table 1. Comparison of different treatment modalities for low-risk prostate cancer}

\begin{tabular}{|c|c|c|c|}
\hline Treatment & Advantages & Disadvantages & Morbidity \\
\hline $\begin{array}{l}\text { Whole-gland } \\
\text { treatment }\end{array}$ & $\begin{array}{l}\text { - Long-term data } \\
\text { - Reduces mortality from PCa } \\
\text { - Eliminates all cancer in prostate }\end{array}$ & $\begin{array}{l}\text { - Treating large number of patients } \\
\text { with insignificant disease } \\
\text { - Morbidity }\end{array}$ & $\begin{array}{l}\text { - Impotence, incontinence, } \\
\text { urethral strictures, bowel } \\
\text { dysfunction }\end{array}$ \\
\hline $\begin{array}{l}\text { Active } \\
\text { surveillance }\end{array}$ & $\begin{array}{l}\text { - Avoids treatment in patients with } \\
\text { insignificant PCa } \\
\text { - Allows for all other treatment } \\
\text { options afterward }\end{array}$ & $\begin{array}{l}\text { - Short-term data } \\
\text { - Loss of opportunity for cure } \\
\text { - Calls for repeat biopsies }\end{array}$ & $\begin{array}{l}\text { - Anxiety } \\
\text { - Mild reduction in HROOL } \\
\text { - Possible sexual dysfunction }\end{array}$ \\
\hline Focal therapy & $\begin{array}{l}\text { - Minimal morbidity } \\
\text { - Destroys index cancer } \\
\text { - Might reduce mortality from PCa } \\
\text { - Allows for other treatment } \\
\text { options afterward }\end{array}$ & $\begin{array}{l}\text { - Very short-term data } \\
\text { - Leaves tumour outside ablated } \\
\text { area } \\
\text { - Calls for repeat biopsies }\end{array}$ & - Minimal \\
\hline
\end{tabular}


In conclusion, focal therapy offers a logical alternative to radical treatment or AS in the management of low-risk PCa patients by combining both the beneficial cancer-control effects of radical treatment and the minimal morbidity of AS. Treating the index lesion of PCa should decrease the risk of local disease progression and might as well decrease PCa-related mortality while maintaining very low morbidity.

In order to confirm these suppositions, image-guided focal therapy needs to be further investigated in rigorously conducted clinical trials to determine its true risks and benefits to patients with low-risk prostate cancer.

From the Department of Surgical Oncology, University Health Network, University of Toronto, Toronto, Ont

This article has been peer reviewed.

Competing interests: None declared.

\section{References}

1. Canadian cancer statistics 2008. Toronto: Canadian Cancer Society, National Cancer Institute of Canada; 2008.

2. Whitmore WF Jr. Localised prostatic cancer: management and detection issues. Lancet 1994;343:1263-7.

3. Thompson IM, Pauler DK, Goodman PJ, et al. Prevalence of prostate cancer among men with a prostatespecific antigen level $\pm 4.0 \mathrm{ng}$ per milliliter. N Engl J Med 2004;350:2239-46.

4. Cooperberg MR, Broering JM, Kantoff PW, et al. Contemporary trends in low risk prostate cancer: risk assessment and treatment. J Urol 2007;178:S14-9.

5. Thompson IM, Goodman PJ, Tangen C CM, et al. The influence of finasteride on the development of prostate cancer. N Engl J Med 2003;349:215-24.

6. Etzioni R, Penson DF, Legler JM, et al. Overdiagnosis due to prostate-specific antigen screening: lessons from U.S. prostate cancer incidence trends. J Natl Cancer Inst 2002;94:981-90.

7. Johansson JE, Andren 0 , Andersson $\mathrm{SO}$, et al. Natural history of early, localized prostate cancer. JAMA 2004;291:2713-9.

8. Draisma G, Etzioni R, Tsodikov A, et al. Lead time and overdiagnosis in prostate-specific antigen screening: importance of methods and context. J Natl Cancer Inst 2009; 101:374-83.

9. Schroder FH. Screening for prostate cancer: an update on recent findings of the European Randomized Study of Screening for Prostate Cancer (ERSPC). Urol Oncol 2008;26:533-41.

10. Draisma $G$, Boer $R, 0$, to SJ, et al. Lead times and overdetection due to prostate-specific antigen screening: estimates from the European Randomized Study of Screening for Prostate Cancer. J Natl Cancer Inst 2003;95:868-78

11. Tsodikov A, Szabo A, Wegelin J. A population model of prostate cancer incidence. Stat Med 2006; 25:2846-66

12. Whitmore WF Jr. Natural history of low-stage prostatic cancer and the impact of early detection. Urol Clin North Am 1990;17:689-97.

13. Bill-Axelson A, Holmberg L, Filen F, et al. Radical prostatectomy versus watchful waiting in localized prostate cancer: the Scandinavian prostate cancer group-4 randomized trial. J Natl Cancer Inst 2008; 100:1144-54.
14. Wei JT, Dunn RL, Sandler HM, et al. Comprehensive comparison of health-related quality of life after contemporary therapies for localized prostate cancer. J Clin Oncol 2002;20:557-66.

15. Sanda MG, Dunn RL, Michalski J, et al. Quality of life and satisfaction with outcome among prostate cancer survivors. N Engl J Med 2008;358:1250-61.

16. Choo R, Klotz L, Danioux C, et al. Feasibility study: watchful waiting for localized low to intermediate grade prostate carcinoma with selective delayed intervention based on prostate specific antigen, histological and/or clinical progression. J Urol 2002;167:1664-9.

17. Klotz L. Active surveillance with selective delayed intervention for favorable risk prostate cancer. Urol Oncol 2006;24:46-50

18. Bacon $C G$, Giovannucci $E$, Testa $M$, et al. The impact of cancer treatment on quality of life outcomes for patients with localized prostate cancer. J Urol 2001;166:1804-10.

19. Galbraith ME, Ramirez JM, Pedro LW. Quality of life, health outcomes, and identity for patients with prostate cancer in five different treatment groups. Oncol Nurs Forum 2001;28:551-60.

20. Litwin MS, Lubeck DP, Spitalny GM, et al. Mental health in men treated for early stage prostate carcinoma: a post-treatment, longitudinal quality of life analysis from the Cancer of the Prostate Strategic Urologic Research Endeavor. Cancer 2002;95:54-60.

21. Arredondo SA, Downs TM, Lubeck DP, et al. Watchful waiting and health related quality of life for patients with localized prostate cancer: data from CaPSURE. J Urol 2004;172:1830-4.

22. Steineck $G$, Helgesen $F$, Adolfsson J, et al. Quality of life after radical prostatectomy or watchful waiting. N Engl J Med 2002;347:790-6.

23. Barocas DA, Cowan JE, Smith JA Jr, et al. What percentage of patients with newly diagnosed carcinoma of the prostate are candidates for surveillance? An analysis of the CaPSURE database. J Urol 2008; 180:1334-5

24. van den Bergh RC, Roemeling S, Roobol MJ, et al. Outcomes of men with screen-detected prostate cancer eligible for active surveillance who were managed expectantly. Eur Urol Epub 2008 Sept 17 ahead of print.

25. Onik G, Narayan P, Vaughan D, et al. Focal "nerve-sparing" cryosurgery for treatment of primary prostate cancer: a new approach to preserving potency. Urology 2002;60:109-14.

26. Ohori M, Eastham JA, Koh H, et al. Is focal therapy reasonable in patients with early stage prostate cancer (CaP): an analysis of radical prostatectomy (RP) specimens. J Urol 2006;175(Suppl):507.

27. Onik G. Rationale for a "male lumpectomy," a prostate cancer targeted approach using cryoablation: results in 21 patients with at least 2 years of follow-up. Cardiovasc Intervent Radiol 2008;31: 98-106.

28. Ellis DS, Manny TB Jr, Rewcastle JC. Focal cryosurgery followed by penile rehabilitation as primary treatment for localized prostate cancer: initial results. Urology 2007;70:9-15.

29. Lindner U, Haider MA, Weersink RA, et al. Image guided photo-thermal focal therapy for localized prostate cancer - phase I trial. J Urol. In press.

30. de Senneville BD, Mougenot C, Moonen CT. Real-time adaptive methods for treatment of mobile organs by MRI-controlled high-intensity focused ultrasound. Magn Reson Med 2007:57:319-30.

31. de Senneville BD, Mougenot C, Quesson B, et al. MR thermometry for monitoring tumor ablation. Eur Radiol 2007:17:2401-10.

32. Mougenot C, Quesson B, de Senneville BD, et al. Three-dimensional spatial and temporal temperature control with MR thermometry-guided focused ultrasound (MRgHIFU). Magn Reson Med 2009;61:603-14.

33. McNichols RJ, Gowda A, Kangasniemi M, et al. MR thermometry-based feedback control of laser interstitial thermal therapy at $980 \mathrm{~nm}$. Lasers Surg Med 2004;34:48-55.

34. Iczkowski KA, Hossain D, Torkko KC, et al. Preoperative prediction of unifocal, unilateral, margin-negative, and small volume prostate cancer. Urology 2008;71:1166-71.

35. Noguchi M, Stamey TA, McNeal JE, et al. Prognostic factors for multifocal prostate cancer in radical prostatectomy specimens: lack of significance of secondary cancers. J Urol 2003;170:459-63.

Correspondence: Dr. John Trachtenberg, Princess Margaret Hospital, 620 University Ave., 4th floor, Rm. 4-926, Toronto ON M5G 2Cl; fax 416 598-9997; trachtenberg@utoronto.ca 